\title{
Comparison and evaluation of several models in prediction of asphaltene deposition profile along an oil well: a case study
}

\author{
Peyman Kor $^{1} \cdot$ Riyaz Kharrat $^{1} \cdot$ Abdoljalal Ayoubi $^{2}$
}

Received: 5 January 2016/Accepted: 18 June 2016/Published online: 2 July 2016

(c) The Author(s) 2016. This article is published with open access at Springerlink.com

\begin{abstract}
Deposition of asphaltenes on the inner surface of oil wells and pipelines causes flow blockage or significant production loss in these conduits. Generally, asphaltenes are stable in reservoir condition; however, change in pressure, temperature, and composition can trigger phase separation and then deposition of asphaltene along the flow stream. Therefore, it is required to identify the possibility of asphaltene precipitation and accurately quantify deposition tendency of these heavy organic molecules. This work is aimed at detailed assessment of the predictive capability of five deposition models available in the literature for calculating the magnitude and profile of asphaltene deposition in wellbores. To end this, firstly we discuss and describe these five models known as Friedlander and Johnstone (Ind Eng Chem 49:1151-1156, 1957), Beal (Nucl Sci Eng 40:1-11, 1970), Escobedo and Mansoori (SPE annual technical conference and exhibition, 1995), Cleaver and Yates (Chem Eng Sci 30:983-992, 1975), and Jamialahmadi et al. (Int J Heat Mass Transf 52:4624-4634, 2009). Afterward, thermodynamic modeling of live oil and a wellbore $P-T$ relationship of the flowing fluid were used in a graphical method in order to identify asphaltene precipitation zone along axial wellbore length. Then, the five models were applied to the wellbore to forecast the deposition tendency of precipitated asphaltene particles and to obtain a profile of deposited asphaltenes. Most importantly,
\end{abstract}

Riyaz Kharrat

kharrat@put.ac.ir

Peyman Kor

Kor.peyman.@gmail.com

1 Petroleum Engineering Department, Petroleum University of Technology, Ahwaz, Iran

2 National Iranian South Oil Company, Ahwaz, Iran a measured deposit profile of the investigated wellbore enabled us to select the most accurate one for estimating the asphaltene deposition rate. The validation method presented in this work reveals that Cleaver and Yates (1975), Jamialahmadi et al. (2009), and Escobedo and Mansoori (1995) models have a satisfactory performance in predicting asphaltene deposition profile along the wellbore when compared to caliper measurement of the well.

Keywords Asphaltene - Deposition - Precipitation · Marrat · Wellbore

\section{List of symbols}

$A_{\mathrm{p}}$ Cross-sectional area of particles in the flow direction $\left(\mathrm{m}^{2}\right)$

$C_{\mathrm{b}} \quad$ Average bulk particle concentration $\left(\mathrm{kg} / \mathrm{m}^{3}\right)$

$C_{\mathrm{d}} \quad$ Drag coefficient

$C_{\mathrm{s}} \quad$ Average surface particle concentration $\left(\mathrm{kg} / \mathrm{m}^{3}\right)$

$D_{\text {pipe }}$ Pipe diameter (m)

$D_{\text {pipe }}^{+} \quad$ Non-dimensional pipe diameter

$d_{\mathrm{p}} \quad$ Particle diameter (m)

$E_{\mathrm{a}} \quad$ Activation energy (kJ)

$f \quad$ Fanning friction factor

$K_{\mathrm{d}} \quad$ Frequency factor $\left(\mathrm{m}^{2} / \mathrm{s}^{2}\right)$

$K_{\mathrm{t}} \quad$ Transport coefficient $(\mathrm{m} / \mathrm{s})$

$\dot{m} \quad$ Mass deposition flux $\left(\mathrm{kg} / \mathrm{s} \mathrm{m}^{2}\right)$

$N \quad$ Particle mass flux $\left(\mathrm{kg} / \mathrm{s} \mathrm{m}^{2}\right)$

$r_{\text {avg }}^{+} \quad$ Non-dimensional average radial distance, $r_{\text {avg }}^{+}=\frac{r_{\text {avg }} V_{\text {avg }} \sqrt{\frac{f}{2}}}{v}$

SP Sticking probability

$S_{\mathrm{p}} \quad$ Stopping distance (m)

$S_{\mathrm{p}}^{+} \quad$ Non-dimensional stopping distance $S_{\mathrm{p}}^{+}=\frac{S_{\mathrm{p}} V_{\text {avg }} \sqrt{\frac{f}{2}}}{v}$

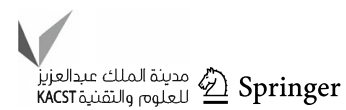


$T \quad$ Temperature $\left({ }^{\circ} \mathrm{F}\right)$

$\tau_{\mathrm{p}} \quad$ Relaxation time (s)

$V_{\text {avg }} \quad$ Average fluid velocity $(\mathrm{m} / \mathrm{s})$

$V_{\mathrm{p}} \quad$ Particle velocity $(\mathrm{m} / \mathrm{s})$

$v \quad$ Kinematic viscosity $\left(\mathrm{m}^{2} / \mathrm{s}\right)$

$\mu \quad$ Dynamic viscosity $(\mathrm{kg} / \mathrm{m} \mathrm{s})$

$\varepsilon \quad$ Eddy diffusivity $\left(\mathrm{m}^{2} / \mathrm{s}\right)$

$\rho_{\mathrm{p}} \quad$ Particle density $\left(\mathrm{kg} / \mathrm{m}^{3}\right)$

$\rho \quad$ Fluid density $\left(\mathrm{kg} / \mathrm{m}^{3}\right)$

\section{Introduction}

The deposition of hydrate, scale, wax, and asphaltene in wellbores and pipelines has been a flow assurance concern for oil and gas industry. Among these concerns, asphaltenes pose a special challenge, because asphaltenes are not well understood and can deposit even at a high temperature. Aspects like light oils to be more prone to develop problems with asphaltene than heavy oils make the problem even more challenging (Sarma 2003). New advancements in enhanced oil recovery and gas lift processes also have been encountered to reduce asphaltene instability, which induces asphaltene precipitation and deposition (Abouie et al. 2015; Fallahnejad and Kharrat 2015; Jafari Behbahani et al. 2012; Nasrabadi et al. 2016).

Asphaltene is the heaviest component of petroleum liquid. Generally accepted definition of this fraction is by solubility regime: insoluble in alkanes such as $n$-pentane (C5) or $n$-heptane (C7), but soluble in aromatic solvents such as toluene, benzene, or pyridine (Mullins et al. 2007). Since asphaltenes comprise a spectrum of individual molecules, within a solubility regime, the exact molecular compositions of many of the molecules are unknown and the material is usually characterized by bulk properties. However, the recent studies pointed that asphaltenes are like an "island" containing a polyaromatic core, and these molecules have relatively small molecular weights ranging from 500 to $100 \mathrm{~g} / \mathrm{mol}$ (Adams 2014).

Generally, asphaltenes are stable in oil phase at reservoir conditions. Variation in temperature, pressure, and composition of oil can induce asphaltene instability. Asphaltene stability in crude oil has been the subject of investigations over many years (Abouie et al. 2016; Arciniegas and Babadagli 2014; Mohebbinia et al. 2014; Prakoso et al. 2016; Sedghi and Goual 2014; Tavakkoli et al. 2011, 2013). The existing models for asphaltene stability can be classified as either thermodynamic or scaling models (Behbahani et al. 2013). Thermodynamic models are based on the complex properties of asphaltene such as interaction coefficient, critical properties, acentric factor, and solubility parameter, while scaling models are based on aggregation and gelation phenomena (Rassamdana et al. 1996). Asphaltene instability is often reported as precipitation or deposition interchangeably; however, the difference is well defined. Precipitation is defined as the formation of a solid phase from the bulk liquid phase, primarily as a function of thermodynamic variables (i.e., pressure, temperature, and composition). Deposition, however, is characterized by the formation and growth of a solid layer on a surface (Juyal et al. 2013). Therefore, precipitation is a prerequisite to asphaltene deposition, but it is not a sufficient condition for deposition (Akbarzadeh et al. 2011). Much progress has been made in the area of asphaltene precipitation in the past several decades, although the mechanism of asphaltene deposition is still not well understood (Alboudwarej et al. 2004; Juyal et al. 2013).

Over the past few decades, several researchers have proposed particulate fouling and asphaltene deposition models to study the solid deposition on the pipe wall. Friedlander and Johnstone (1957) proposed that large particles $(\sim 1 \mu \mathrm{m}$ diameter) radially transported by virtues of eddy diffusion and particle inertia. The model predictions were compared with experimental data where a fairly good agreement was obtained. Beal (1970) employed aspects of the previous model (Friedlander and Johnstone 1957) and developed a model suitable for both small and large particle depositions. The author considered that small particles would be transported by Brownian motion and eddy diffusion, as it was proposed by Lin et al. (1953), while large particles would be transported by eddy diffusion and particle inertia, as it was proposed by Friedlander and Johnstone (1957). In contrast to the previous researchers, Cleaver and Yates (1975) followed a different approach, applying probabilistic theory, to develop the particle deposition model. In their calculations, the simple mechanistic model was implemented and artificial boundary conditions were disregarded. A fairly good agreement was found after comparison of the developed model predictions (Cleaver and Yates 1975) with experimental data at the range of particle size smaller than $(<1 \mu \mathrm{m})$.

Escobedo and Mansoori (1995) first developed asphaltene deposition model based on a previous model (Beal 1970) used for aerosol (microscopic liquid or solid particles dispersed on air currents) deposition. The model was developed by accounting for both diffusive and convective mechanisms for transport of asphaltene particle to the pipe wall (Paes et al. 2015; Zeinali Hasanvand et al. 2016).

Jamialahmadi et al. (2009) performed experiments to measure the rate of asphaltene deposition in a flow-loop apparatus. The experimental results showed that the deposition rate increases by increasing the asphaltene mass fraction and surface temperature and decreases by increasing the crude oil velocity. 
Vargas et al. (2010) developed a model consisting of sub-models describing the particle precipitation, agglomeration, transport, and deposition on the wall. The aggregation and deposition stages are modeled using pseudofirst-order reactions. The particle transport is described by the convection-diffusion equation. The model contains several tuning parameters that have to be identified based on the experimental data. In the most recent work, Hashmi et al. (2015) assumed that diffusion is the main driving mechanism in asphaltene deposition on the metal surface and introduced a new deposition model. Asphaltene deposition was assessed by injecting precipitating petroleum fluid mixtures into a small metal pipe, which results in deposition and clogging. Measurement of pressure drop across the pipe was used to understand dynamics of asphaltene deposition. The agreement was found between model predictions and experimental data. However, the model was developed for laminar flow, and further investigation is required to apply the model to turbulent flow of oil from a wellbore.

Shirdel et al. (2012) studied the application of Friedlander and Johnstone (1957), Beal (1970), Cleaver and Yates (1975), and Escobedo and Mansoori (1995) models to predict the published experimental data. In the first part of their paper, they used Friedlander and Johnston's (1957) aerosol data set. In the second part, they used Jamialahmadi et al.'s (2009) experimental data set.

In this work, the oil well in south Kuwait's Marrat reservoir was selected to study asphaltene precipitation and deposition along the production tube. An appropriate thermodynamic model (solid model) was used to identify the asphaltene precipitation zone, and then five deposition models were applied to the wellbore and compared with reported deposit, a work similar to Shirdel et al. (2012), but in the field scale.

\section{Deposition models}

The asphaltene deposition models consist of three major modules: (1) particle transport toward the wall surface, (2) particle attachment process to the surface, and (3) particle concentration gradient between fluid bulk and the wall surface. Contribution of these modules in asphaltene deposition rate can be expressed according to the following relationship:

$\dot{m}=K_{\mathrm{t}} \times \mathrm{SP} \times\left(C_{\mathrm{b}}-C_{\mathrm{s}}\right)$

In Eq. (1), $K_{\mathrm{t}}$ is the transport coefficient which considers the macroscopic and microscopic mechanisms, SP is the sticking probability, and $\left(C_{\mathrm{b}}-C_{\mathrm{s}}\right)$ is the concentration gradient between fluid bulk and wall surface.

\section{Transport coefficient}

For accurate calculation of asphaltene deposition rate, comprehensive knowledge of effective mechanisms contributing in deposition process is necessary. In order to study this complex mass transfer problem, the asphaltene deposition was placed within a general context of particle deposition during a turbulent flow.

A parameter which is related to particle and flow characteristics is particle relaxation time. The physical meaning of the relaxation time comes from Stokes stopping distance of an immersed particle. Stokes stopping distance is defined as the distance a particle (mass, $m_{\mathrm{p}}$, diameter, $d_{\mathrm{p}}$, and density, $\rho_{\mathrm{p}}$ ), with an initial velocity $V_{0}$, travels in freeflight through a stagnant fluid before it stops because of drag forces. The force balance on the particle in horizontal direction results in (Friedlander and Johnstone 1957):

$m_{\mathrm{p}} \frac{\mathrm{d}^{2} x}{\mathrm{~d} t^{2}}=-6 \pi \mu r_{\mathrm{p}} \frac{\mathrm{d} x}{\mathrm{~d} t}$

where $x$ is the particle position at a given time $t$. The particle's velocity can be evaluated by integrating Eq. 1 with boundary condition $\left.\frac{\mathrm{d} x}{\mathrm{~d} t}\right|_{t=0}=V_{0}$ and considering that the particle's mass is given by $4 \pi r_{\mathrm{p}}^{3} \rho_{\mathrm{p}} / 3$ (Paes et al. 2015):

$\frac{\mathrm{d} x}{\mathrm{~d} t}=V_{0} \exp \left(-t / \tau_{\mathrm{p}}\right)$

The stopping distance, $S_{\mathrm{p}}$, can be evaluated by considering that $x$ approaches $S_{\mathrm{p}}$ when $t$ tends to infinity:

$S_{\mathrm{p}}=\tau_{\mathrm{p}} V_{\mathrm{p}}$

where $t_{\mathrm{p}}$ is the particle relaxation time, defined as

$\tau_{\mathrm{p}}=\frac{\rho_{\mathrm{p}} d_{\mathrm{p}}^{2}}{18 \mu}$

Particle relaxation time is converted to dimensionless form as

$\tau_{\mathrm{p}}^{+}=\frac{\rho_{\mathrm{p}} d_{\mathrm{p}}^{2}}{18 \mu} \times \frac{\frac{f}{2} V_{\mathrm{avg}}^{2}}{v}$

where $V_{\text {avg }}$ is the average liquid velocity $(\mathrm{m} / \mathrm{s})$ and $f$ is the fanning friction factor and can be calculated from classical Blasius equation (Prandtl 1935) for smooth tube flow:

$f=\frac{0.3164}{\operatorname{Re}^{0.25}}$

Disregarding the electrostatic and thermophoresis effects between surface and particles, we may have three different mechanisms for particles deposition. Based on dimensionless particle relaxation time, one of the mechanisms becomes dominant (Shirdel et al. 2012). We define these mechanisms as: diffusion $\left(\tau_{\mathrm{p}}^{+}<0.1\right)$, inertia $\left(0.1<\tau_{\mathrm{p}}^{+}<10\right)$, and impaction $\left(\tau_{\mathrm{p}}^{+}>10\right)$ (Epstein 1997). 
In the following sections, we briefly discuss the five selected models: Friedlander and Johnstone (1957), Beal (1970), Cleaver and Yates (1975), Escobedo and Mansoori (1995), and Jamialahmadi et al. (2009). The mathematical equation of each model is provided in Table 1.

\section{Friedlander and Johnstone model}

Friedlander and Johnstone (1957) applied the classical approach in order to obtain the transport coefficient $\left(K_{\mathrm{t}}\right)$. In this approach, mass transfer flux was formulated by analogy to the momentum transfer in turbulent flow. The shear stress which is momentum flux is defined as:

$\tau=(\mu+\rho \varepsilon) \frac{\mathrm{d} V}{\mathrm{~d} y}$

By analogy, using molecular diffusivity instead of kinematic viscosity and eddy diffusivity instead of viscosity, we obtain mass transfer flux as:

$N=\left(D_{\mathrm{m}}+\varepsilon\right) \frac{\mathrm{d} C}{\mathrm{~d} y}$

In order to calculate the total mass flux, authors used Lin et al.'s (1953) model in which flow regions are divided into three sections known as a sub-laminar layer, a buffer region, and turbulent core where the velocity and eddy viscosity distribution are correlated at each region. Friedlander and Johnstone (1957) performed integration of concentration difference for three different flow zones. The integration intervals consist of the stopping distance from the wall to the edge of the sub-laminar layer, then from the sub-laminar layer to the end of the buffer zone, and finally, from the buffer zone to the turbulent core. In addition, by considering large particles, they neglected Stokes-Einstein diffusivity (Brownian motion). Hence, Friedlander and Johnstone (1957) calculated the transport coefficient in three conditions, depending on the stopping distance value, which can be located inside the sublaminar layer, buffer zone, or turbulent core.

\section{Beal model}

Contrary to Friedlander and Johnstone (1957), Beal (1970) developed a model suitable for both small and large particles by considering Brownian diffusion. In addition, Beal (1970) assumed a linear equation for mass and momentum flux.

\section{Cleaver and Yates model}

Cleaver and Yates (1975) applied a stochastic approach to obtain the transport coefficient. Stagnation point flow model was assumed for the motion of fluid toward the wall, and a model accounting for both upsweeps and downsweeps of the fluid in the wall region was developed.

\section{Escobedo and Mansoori model}

Escobedo and Mansoori (1995) developed a model similar to Beal's (1970); however, they did not use the Reynolds analogy for the turbulent core diffusion.

\section{Jamialahmadi et al.'s model}

Jamialahmadi et al. (2009) proposed that the transport coefficient of the submicron asphaltene particles can be obtained from empirical correlations for forced convective heat transfer. Chilton and Colburn's analogy was used by replacing the Nusselt and Prandtl numbers by the Sherwood and Schmidt numbers in Prandtl equation. Assuming the Schmidt number in the order of $10^{6}$ and some manipulation, they further simplified the model.

As it can be noticed, the equation for the transport coefficient differs very slightly from those found by Cleaver and Yates (1975) model; however, they were developed in entirely two different approaches. Hence, in this work we will discuss the Cleaver and Yates (1975) model which can be also representative of Jamialahmadi et al.'s (2009) model.

\section{Sticking process}

Once the asphaltene particles reach the wall, a fraction of them sticks to the wall. This fraction can be defined as follows (Watkinson 1968):

$\mathrm{SP} \propto \frac{\text { Adhesive bond between particle and surface }}{\text { Average shear stress on particle at surface }}$

$\mathrm{SP}=\mathrm{SP}_{0} \frac{F_{\text {adh }}}{F_{\text {drag }}}$

One can find from Eq. (10) that when $\mathrm{SP}=1$, the deposition rate is limited by transport coefficient and mass transfer controls the process. In this case, all particles arriving at the wall stick to it. The adhesion force generally obeys Arrhenius expression and can be written as (Watkinson 1968)

$F_{\text {adhesive }}=F_{\mathrm{a}} e^{\frac{-E_{\mathrm{a}}}{R T_{\mathrm{s}}}}$

where $F_{\mathrm{a}}$ is a constant, $E_{\mathrm{a}}$ is the activation energy, and $T_{\mathrm{s}}$ is the surface temperature. On the other hand, the drag force on the particle is given by:

$F_{\text {drag }}=A_{\mathrm{p}} \frac{\rho V_{\mathrm{avg}}^{2}}{2} C_{\mathrm{d}}$

Therefore, by substituting equations in sticking probability equation:

$\mathrm{SP}=\mathrm{SP}_{0} \frac{2 F_{\mathrm{a}} e^{-\frac{E_{\mathrm{a}}}{R T_{\mathrm{s}}}}}{C_{\mathrm{d}} A_{\mathrm{p}} \rho V_{\mathrm{avg}}^{2}}$ 


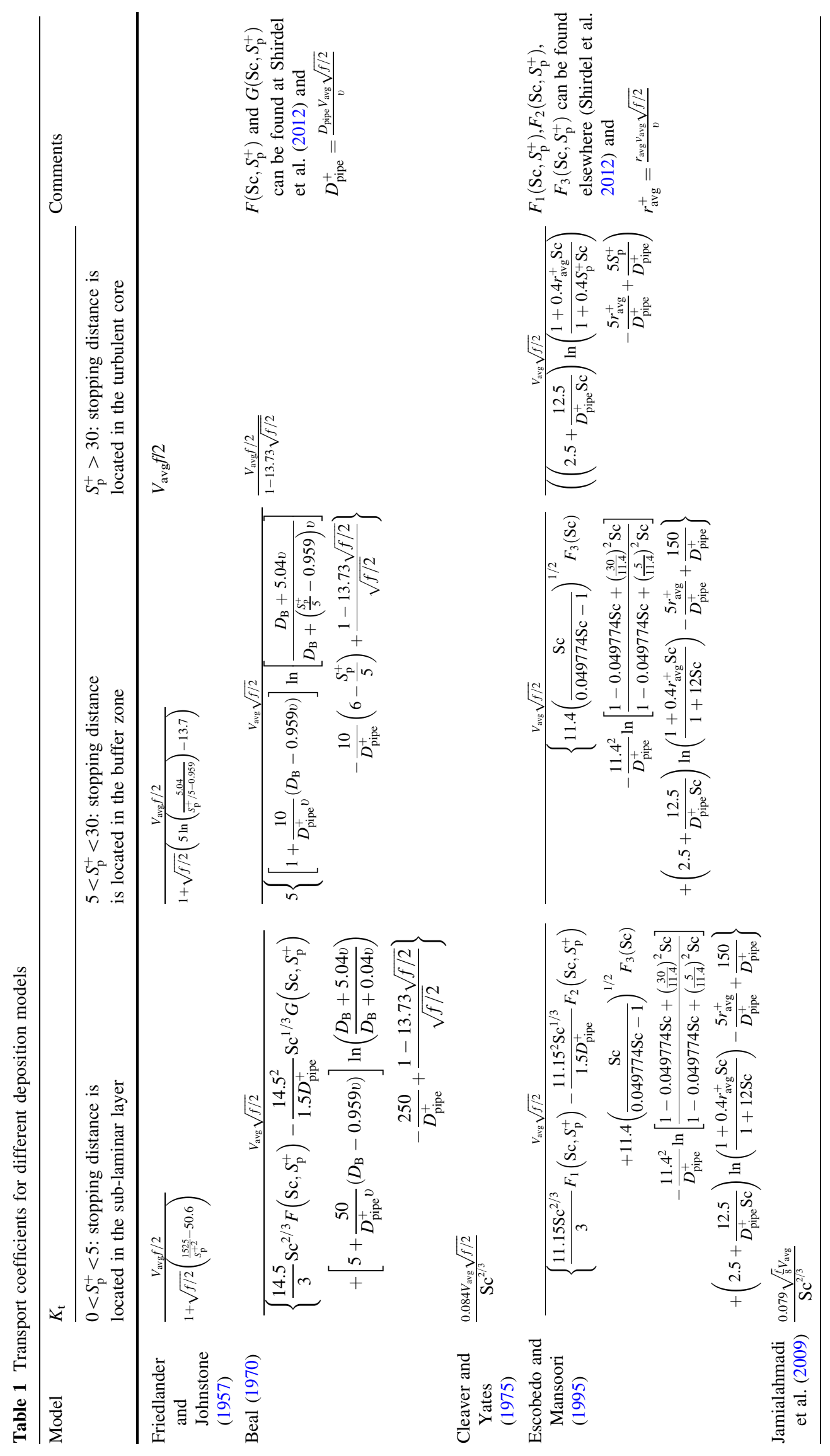


Table 2 Parameters of sticking probability and mean diameter of asphaltene particle

\begin{tabular}{ll}
\hline Property & Value \\
\hline Particle diameter $\left(d_{\mathrm{p}}\right)$ & $3.281 \times 10^{-7} \mathrm{ft}$ \\
Activation energy $\left(E_{\mathrm{a}}\right)$ & $28.079 \mathrm{BTU} / \mathrm{lb} \mathrm{mol}$ \\
Frequency factor $\left(K_{\mathrm{d}}\right)$ & $6.824 \times 10^{10} \mathrm{ft}^{2} / \mathrm{s}^{2}$ \\
\hline
\end{tabular}

which can be written as:

$\mathrm{SP}=K_{\mathrm{d}} \frac{e^{-\frac{E_{a}}{R T_{\mathrm{s}}}}}{V_{\mathrm{avg}}^{2}}$

where $E_{\mathrm{a}}$ and $K_{\mathrm{d}}$ are activation energy and frequency factor, respectively, which are related to asphaltene particle and tubing properties and calculated from experimental tests. Unfortunately, these parameters are not available for Marrat oil well. Jamialahmadi et al. (2009) conducted experiments on the deposition of asphaltene particles from Middle East oil and by curve fitting found that $E_{\mathrm{a}}=65.3 \mathrm{~kJ} / \mathrm{mol}$ and $K_{\mathrm{d}}=9.76 \times 10^{8}$. We used the same value for $E_{\mathrm{a}}$ and a reasonable value in the same for $K_{\mathrm{d}}$. Table 2 represents these values and other parameters in the deposition models.

\section{Particle concentration gradient}

$\left(C_{\mathrm{b}}-C_{\mathrm{s}}\right)$ is the concentration drop which provides the driving force between solution bulk and solid-fluid interface. $C_{\mathrm{b}}$ is the average bulk particle concentration. In the system containing oil and solid phase, the average bulk particle concentration is predicted through a thermodynamic equilibrium between oil and a solid phase which will be described in the next section. $C_{\mathrm{s}}$ is the surface particle concentration and is known as a lower boundary condition of particle deposition flux. This boundary is regarded as a zero particle concentration at the pipe wall at most of the practical use.

\section{Asphaltene precipitation model}

In this study, we use the solid model introduced by Gupta (1986) to predict the amount of asphaltene precipitation and Peng and Robinson (1976) equation of state to model the oil and gas behavior. We used Nghiem et al. (1993) method for characterizing the asphaltene solid phase, in which at equilibrium conditions, the fugacity of each component in all phases (e.g., solid, liquid, and gas) is the same as presented in the following equation:

$$
\begin{aligned}
f_{i, o} & =f_{i, g}, \quad i=1, \ldots, n_{c} \\
f_{n_{c}, o} & =f_{\text {asph }}
\end{aligned}
$$

The fugacity of each component in the oil and gas phase is calculated from the Peng and Robinson (1976) equation of state, and the fugacity of asphaltene in the solid phase is calculated from (Nghiem et al. 1993; Nghiem and Coombe 1997):

$\ln f_{\text {asph }}=\ln f_{\text {asph }}^{*}+\frac{V_{\text {asph }}\left(P-P^{*}\right)}{R T}$

where $P^{*}$ is the onset pressure of asphaltene at temperature $T$ and $f_{\text {asph }}^{*}$ is the fugacity of asphaltene in the solid phase at temperature $T$ and pressure $P^{*}$.

\section{Wellbore and fluid data}

In order to compare and evaluate the performance of models in field scale, an oil wellbore with measured asphaltene deposition profile is required. Sufficient thermodynamic properties of live oil should be available for accurate fluid characterization. Hydrodynamic data of wellbore are also required for predicting pressure and temperature route along the wellbore. The only reported asphaltene deposition profile was provided by Kabir et al. (2001), in which a caliper measurement was run in Marrat oil wellbore in south Kuwait's oil field. Operating conditions of this wellbore are reported in Table 3 (Kabir et al. 2001). A few thermodynamic data and SARA test analysis of the oil from the same field have been reported by the same authors in Kabir and Jamaluddin (2002) also are provided in Table 3 .

In addition, Table 4 summarizes the results of saturation pressure and upper and lower onset pressure of the oil at different temperatures (Jamaluddin et al. 2002; Kabir and Jamaluddin 2002). Kurup et al. (2011) have also provided a hydrodynamic and $P-T$ relationship of this wellbore from an internal database of Chevron. With this available information, it was possible to apply the models to this wellbore.

Table 3 Operating condition of Marrat oil well and PVT characteristics of studied oil

\begin{tabular}{llllll}
\hline Property & Value & Property & Value & Property & Value \\
\hline Well depth (ft) & 15,000 & GOR (SCF/ST) & 1100 & Aromatics (SARA test), \%w/w \\
Production rate, STB/D & 5000 & API & 39 & Resins (SARA test), \% w/w \\
Production string ID (in.) & 2.75 & Saturates (SARA test), \%w/w & 68.3 & Asphaltene (n-pentane insoluble), \%w/w $\quad 1.6$ \\
\hline
\end{tabular}


Table 4 Saturation pressures along with upper and lower offset pressures of oil at different temperatures

\begin{tabular}{llll}
\hline $\begin{array}{l}\text { Temperature } \\
\left({ }^{\circ} \mathrm{F}\right)\end{array}$ & $\begin{array}{l}\text { Upper onset } \\
\text { pressure }(\mathrm{psi})\end{array}$ & $\begin{array}{l}\text { Saturation } \\
\text { pressure }(\mathrm{psi})\end{array}$ & $\begin{array}{l}\text { Lower offset } \\
\text { pressure }(\mathrm{psi})\end{array}$ \\
\hline 210 & 6854 & 3221.2 & \\
219.2 & 6587 & 3283 & \\
230 & 6419 & 3276 & 1959.45 \\
241 & 6225 & 3289 & \\
\hline
\end{tabular}

\section{Solution procedure for predicting deposition profile}

The wellbore was discretized to 50 grids of $300 \mathrm{ft}$ lengths in the z-direction. Pressure and temperature were obtained in the center of each grid from $\mathrm{P}$ versus $\mathrm{T}$ relationship provided by (Kurup et al. 2011). However, in this work, pressure and temperature versus depth were required. Hence, it was assumed that pressure varies from bottomhole pressure $(8400 \mathrm{psi})$ until wellhead pressure (350 psi) linearly. And then, the temperature of each grid with known pressure was obtained from available $P-T$ relationship. The pressure profile is not entirely linear in wellbores; however, because of lack of data, at this point, this assumption was made. The obtained $P-T$ relationship in this work was compared with field data reported in the work of Kurup et al. (2011) in Fig. 1.

With available pressure, temperature at each grid, and composition of the fluid, phase equilibrium calculation was done using (Peng and Robinson 1976) equation of state in order to calculate the number of phases, phase's density, and molar volume of each phase, and suitable correlations were used to predict the PVT properties of the flowing fluid. WINPROP, a phase behavior modeling software developed by computer modeling group (CMG), was employed to predict the weight percent of the precipitated asphaltene. In MATLAB programming software, all mentioned calculations were combined in a single program



Fig. 1 Pressure and temperature of flowing fluid along the oil wellbore. **Kurup et al. (2011) code and coupled with deposition models. The flowchart of the method is shown in Fig. 2.

\section{Results and discussion}

\section{Thermodynamic characterization and modeling of asphaltene precipitation}

WINPROP was employed to perform the equilibrium flash calculation and also the construction of the solid model for modeling the asphaltene precipitation. To do the first, a common regression was run to tune the cubic EOS to PVT experimental data. Bubble point pressure at reservoir temperature $\left(241^{\circ} \mathrm{F}\right)$ and gas-oil ratio (GOR) were taken into account as important parameters in the tuning process. As illustrated in Fig. 3, the thermodynamic model prediction of saturation pressures for different temperatures (the dark blue line) matches very well with experimental data. For modeling the asphaltene precipitation, the heaviest plus fraction was split into a non-precipitating fraction $\mathrm{C}_{22 \mathrm{~A}+}$ and a precipitating fraction $\mathrm{C}_{22 \mathrm{~B}+}$. Asphaltene component parameters including solid molar volume $\left(\mathrm{V}_{\mathrm{asph}}\right)$, and binary interaction coefficients $(\delta)$ between $\mathrm{C}_{22 \mathrm{~B}+}$ and the light components up to and including $\mathrm{C}_{5}$ should be adjusted to match with the experimental data. An experimental data set of asphaltene onset pressures were taken as reference pressure $P^{*}$ in the solid-phase model at each isotherm. The asphaltene precipitation envelope (APE) was determined by performing flashes at varying pressures for a number of temperatures. Flash calculations using a small pressure step are used to locate the precipitation onset pressures and asphaltene offset pressures. These calculated onset and offset pressures were taken together to define the asphaltene precipitation envelope. The orange line in Fig. 3 represents the asphaltene onset pressure curve constructed from this method, where the green line represents the prediction of asphaltene offset pressures.

Figure 4 shows the comparison of the well-matched model predictions with the experimental test results. The model predictions were found after several isothermal runs at 120 and $241{ }^{\circ} \mathrm{F}$. When the model predictions matched well with the experimental data, the values of $V_{\text {asph }}$ and $\delta$ were found to be 0.456 and $0.17 \mathrm{l} / \mathrm{mol}$, respectively. As it can be seen for $241^{\circ} \mathrm{F}$, the asphaltene starts to precipitate at the pressure of $7000 \mathrm{psi}$ and reaches its maximum point of precipitation at the pressure of around 3000 psi. This observation is in agreement with the fact that normally the asphaltene precipitation reaches the maximum at bubble point pressure which is also around 3000 psi as shown in Fig. 3 for $241^{\circ} \mathrm{F}$. This matched model was used for prediction of weight percent of precipitated asphaltene from crude oil at any other temperature and pressure. 
Fig. 2 Computational procedure for prediction of asphaltene profile along the wellbore

Fig. $3 P-T$ diagram of oil/ asphaltene system at different pressures and temperatures


\section{Fluid and flow characteristics along the wellbore}

During the oil and gas production from the reservoir to the surface facility, fluid flows along a path which has a wide range of pressure and temperature variations. In fact, changes in the thermodynamic conditions influence the fluid and flow properties along the wellbore. Variations of oil formation volume factor and gas formation volume factor are shown in Fig. 5. The figure shows that at depth around $5000 \mathrm{ft}, B_{\mathrm{o}}$ starts to decrease until it reaches $1.07 \mathrm{SCF} / \mathrm{STB}$ at the wellhead. In addition, zero values for gas formation factor below $\sim 5000 \mathrm{ft}$ show that the production fluid is undersaturated from bottomhole to the depth of $\sim 5000 \mathrm{ft}$.

As shown in Fig. 6, the evolution of gas bubbles from production fluid causes an increase in gas superficial velocity and decrease in oil superficial velocity. Oil superficial velocity starts at a rate of $11.58 \mathrm{ft} / \mathrm{s}$ at the bottom of the wellbore and increases slowly due to decreasing liquid density until the depth around $5000 \mathrm{ft}$ when it reaches $11.64 \mathrm{ft} / \mathrm{s}$. In addition, the gas superficial velocity reaches $10.65 \mathrm{ft} / \mathrm{s}$ at the top of the wellbore, where the gas phase consists of most portion of production fluid. 




Fig. 4 Comparison of thermodynamic model predictions and reported experimental data for weight percent of precipitated asphaltene at $T=241^{\circ} \mathrm{F}$ and $T=120^{\circ} \mathrm{F}$

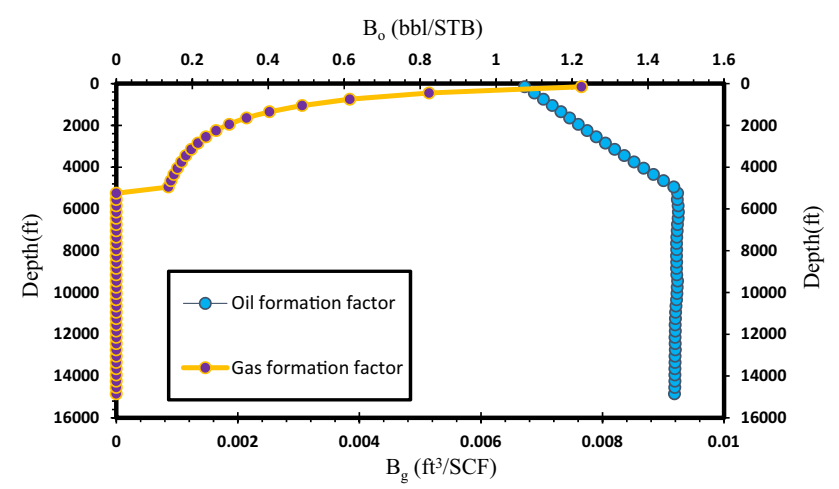

Fig. 5 Variations in oil and gas formation volume factors along the wellbore



Fig. 6 Oil and gas superficial velocity profiles along the wellbore during oil production

\section{Asphaltene precipitation}

Changes in pressure and temperature of the fluid throughout the well column are also influential in the thermodynamic conditions of the fluid. Depending on design and operational conditions of the well column, a part or all of the asphaltene precipitation boundaries may be crossed out as fluid flows upward. The identifying unstable region of asphaltene along the well is a prerequisite for prediction of the deposition profile. This precipitation region can be represented by the intersection of $P-T$ relationship with asphaltene upper and lower boundaries. As shown in Fig. 7a, until the point of pressure 7177 psi and temperature $214.7^{\circ} \mathrm{F}$ in which the fluid is at reservoir conditions, the fluid is at the single phase and asphaltene is stable in oil, which represents the stable region (1). As the well $P-T$ relationship intersects upper asphaltene boundary at (7177 psi, $214^{\circ} \mathrm{F}$ ), the thermodynamic equilibrium of oil/ asphaltene was disturbed and the asphaltene starts to precipitate and the unstable region (2) begins. Then, as pressure and temperature decrease continuously, more asphaltene precipitates. After that, when the well $P-T$ relationship intersects bubble pressure curve, the gas comes out of the oil/asphaltene mixture. At this point, the system consists of three phases, namely liquid oil, solid asphaltene, and released gas. Releasing the light components at bubble point, which are normally precipitating agent of asphaltene, makes the oil a better solvent for asphaltene, and hence, the asphaltene starts to become more stable in oil until the intersection of $P-T$ relationship with a lower boundary condition at (1650 psi, $\left.139.5^{\circ} \mathrm{F}\right)$. Finally, in the region (3), the asphaltene becomes completely stable in liquid oil and system becomes a single liquid phase.

This procedure can be used as a graphical method to map out the precipitation zone in Marrat oil well which is shown in Fig. 7b. The oil starts to precipitate at $7177 \mathrm{psi}$ and $241^{\circ} \mathrm{F}$ along its $P-T$ relationship. The corresponding depth for this pressure is around $1270 \mathrm{ft}$ in the $15,000 \mathrm{ft}$ length well. Asphaltene precipitation continues until the pressure of $1650 \mathrm{psi}$, at the depth of $2500 \mathrm{ft}$, after which asphaltene precipitation ceases.

The method enabled us to identify the precipitation zone along the wellbore. The next step is quantifying the asphaltene precipitation tendency in the precipitation zone. The thermodynamic modeling of the oil/asphaltene system in the first section was used to predict the weight percent of the oil phase which precipitated. Figure 8 shows this quantity along the production tubing. The weight percent of the precipitated asphaltene is converted to asphaltene concentration by multiplying it by the live oil density to use as the asphaltene particle concentration in Eq. 1.

\section{Asphaltene transport coefficients and sticking probability}

Although the quantity of precipitated asphaltene is crucial, it is equally important to predict the transport of these precipitated particles toward the tubing wall. This process was described early in the modeling approach as the transport coefficient, representing the rate of transportation. In Fig. 9, we investigate this parameter for the four models along Marrat oil wellbore. As can be seen in all models, 


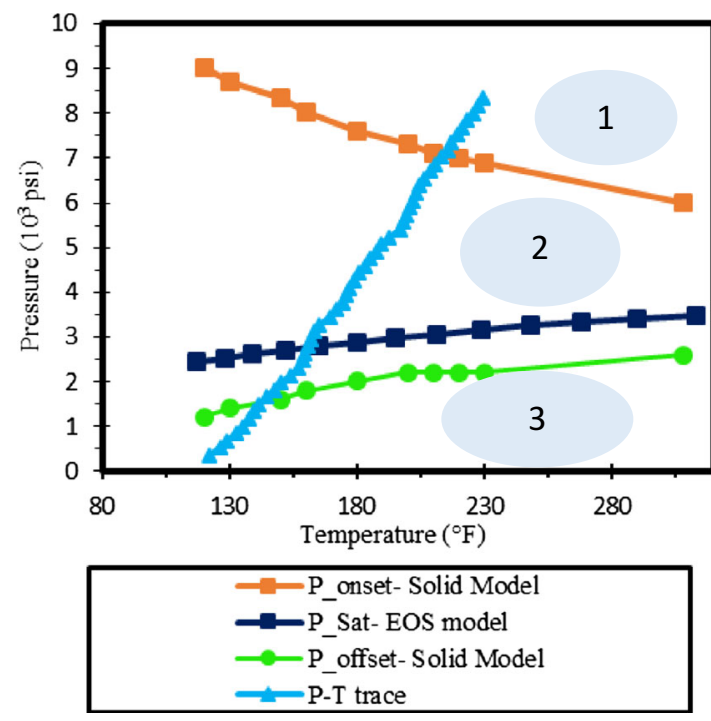

(a)

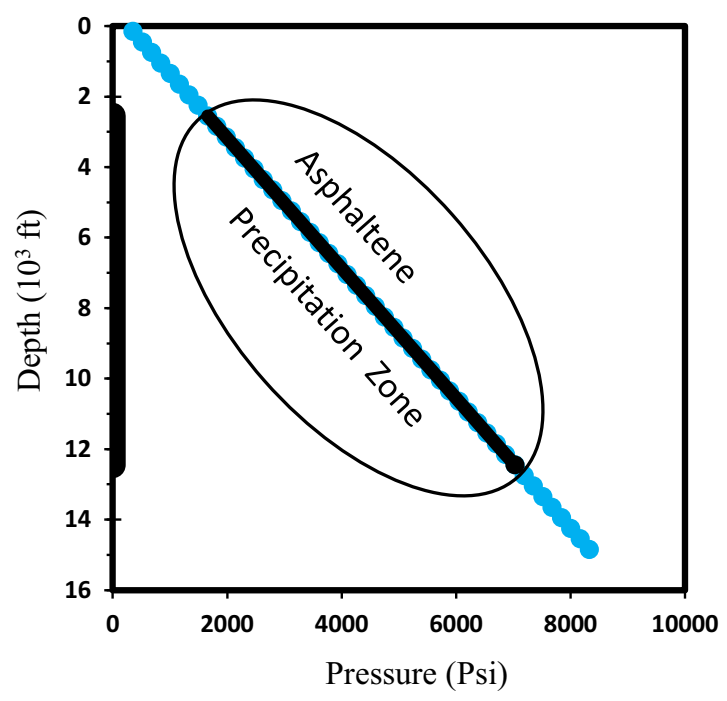

(b)

Fig. 7 a Intersection of $P-T$ relationship with upper and lower boundaries of the asphaltene precipitation envelope. b Schematic diagram of the asphaltene precipitation zone

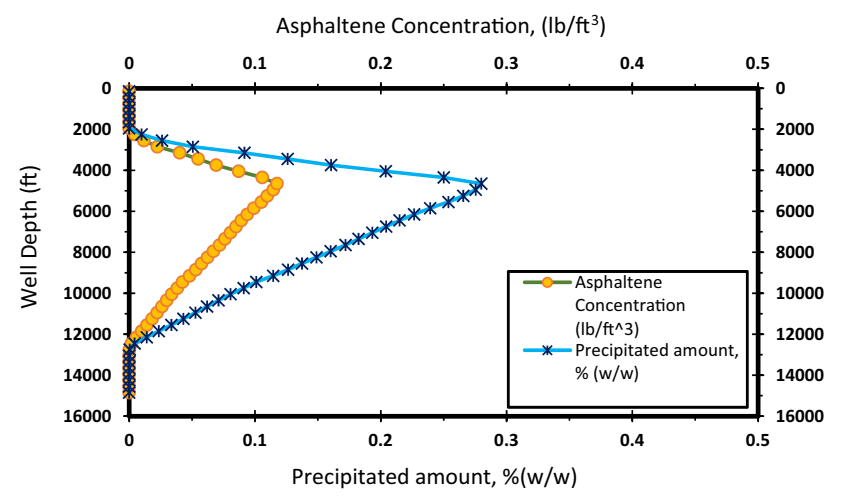

Fig. 8 Profiles of weight percent of precipitated asphaltene and asphaltene concentration along the wellbore

starting from wellbore shoe at $15,000 \mathrm{ft}$, the transport coefficient starts to increase smoothly until the depth of around $5000 \mathrm{ft}$.

The four models have been obtained in an entirely different manner; however, their uniform increase until a specific depth is the point of interest. To analyze this behavior, we consider the simplest models Cleaver and Yates (1975) or Jamialahmadi et al. (2009) which are comprised of just three parameters $\left(f, V_{1}\right.$, and Sc). The trend of these parameters along the wellbore can be helpful to understand the above behavior. This analysis will also lend light for understanding the other model's trend. Figure 10a shows variations in the fanning factor $(f)$ and the liquid velocity $\left(V_{1}\right)$ along the wellbore which are proportional to the transport coefficient. Figure $10 \mathrm{~b}$ shows variation in Schmidt number $(\mathrm{Sc})$ which is inversely proportional to $K_{\mathrm{t}}$.

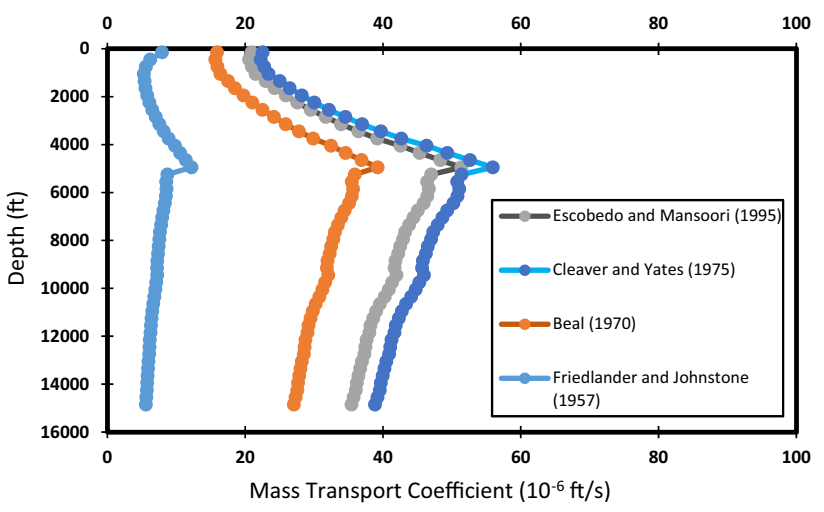

Fig. 9 Comparison of four models in predicting the asphaltene transport coefficient $\left(K_{\mathrm{t}}\right)$

Figure 10a shows that the fanning factor $(f)$ continuously decreases along the production tube until the depth of $\sim 5000 \mathrm{ft}$ and cannot contribute to the increase in the transport coefficient. Liquid velocity starts to increase as oil expands during liquid-phase oil production; however, this increase continues until wellhead facility and cannot be regarded to describe the increase in transport coefficient until depth around $5000 \mathrm{ft}$. The last parameter shows a trend which is the key to our understanding. As shown in Fig. 10b, Schmidt number decreases as oil move toward the depth around $5000 \mathrm{ft}$. In fact, during oil expansion along the wellbore, diffusivity coefficient $\left(D_{\mathrm{B}}\right)$ increases due to decreasing oil viscosity which is inversely proportional to diffusivity coefficient. This observation suggests that asphaltene deposition in production tubing is a 


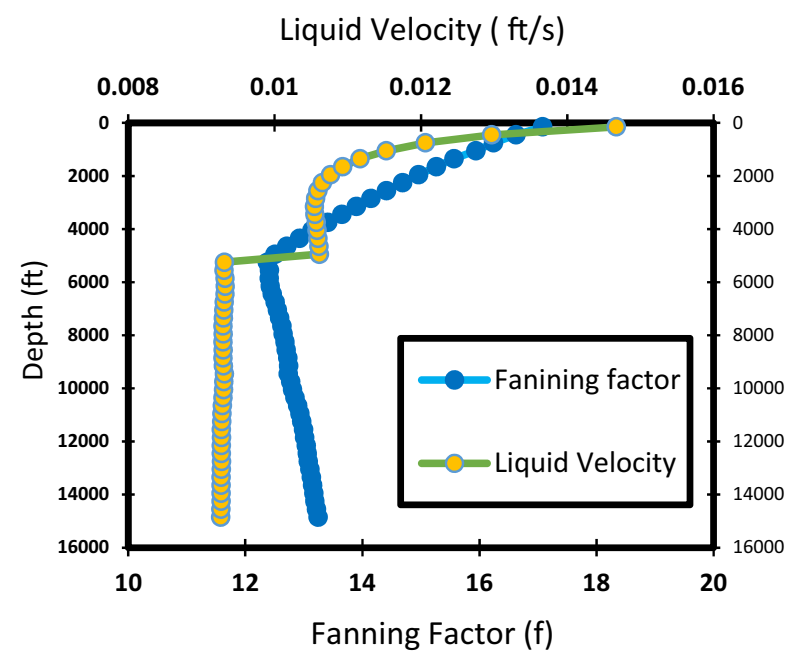

(a)

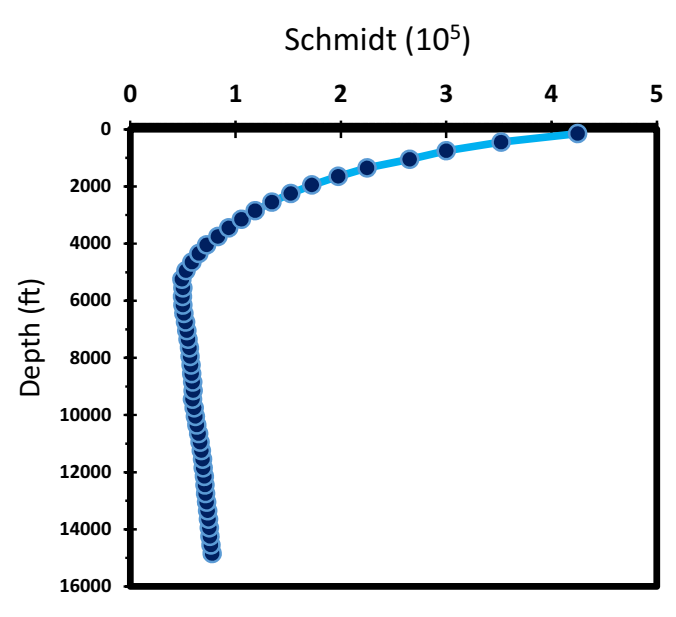

(b)

Fig. 10 a Change in the liquid-phase velocity and fanning factor, $\mathbf{b}$ change in Schmidt number along the wellbore

diffusion-driven process which supports our earlier understanding about this phenomenon (Hashmi et al. 2015).

\section{Asphaltene deposition profile}

The multistep process including asphaltene precipitation, asphaltene transportation, and attachment of asphaltene particle to the metal surface is required to form deposit layer. The first two steps were analyzed in previous sections, and they were quantified along the wellbore from bottomhole to the wellhead in Figs. 8 and 9. Figure 11 represents a change in the fraction of asphaltenes that attach to the tube's inner wall surface when they transported toward the wall. Recalling $\mathrm{SP} \propto \frac{1}{V^{2}}$, as fluid flows upward, oil expands and liquid velocity increases, and thus the adherency of asphaltene particles to the metal surface decreases.

Figure 12 shows the comparison of four model predictions with real measurement of asphaltene thickness from

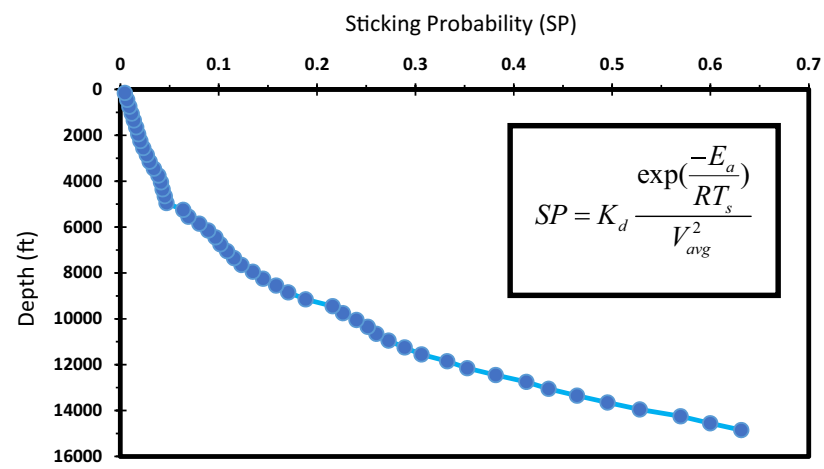

Fig. 11 Change in sticking probability (SP) in the wellbore caliper along the Marrat oil well. Although the caliper measurements reported in the work of Kabir and Jamaluddin (2002) show the whole range of deposited asphaltene thickness along the depth, in this work mean value of reported measurements from the caliper was used to make the comparison more illustrative. The black line in Fig. 12 represents the mean value of reported deposit profile of Marrat oil wellbore along the production string. Unfortunately, the caliper measurement was not run from depth around $15,000 \mathrm{ft}$ in order to clearly find where asphaltene deposition starts to build. As we discussed in section "Asphaltene precipitation," all models show that asphaltene appears somewhat around the depth of $12,500 \mathrm{ft}$. This depth is in close agreement with that of Kurup et al. (2011) where they studied this wellbore with (ADEPT) deposition simulator and concluded that the deposition starts at 12,000 ft. In addition, as we can see, Cleaver and Yates (1975) model predicts asphaltene deposition profile more closely to the mean value of caliper measurement. At the maximum deposition zone, this model predicts $0.47 \mathrm{in}$. asphaltene deposit layer after 2 months of oil production. Schematic of asphaltene deposition profile formed with Cleaver and Yates (1975) and Escobedo and Mansoori (1995) models reveals that although they are completely different in the way developed, their predictions are similar to each other. This finding was also observed in the work of Shirdel et al. (2012) where these models were compared in laboratory scale.

Figure 13 shows a comparison of the model predictions with caliper measurements at 2550, 2950, 3500, and 4000 Reynolds numbers. The corresponding depths for these Reynolds numbers are 3150, 3750, 10,000, and $5850 \mathrm{ft}$. The bar graph in this figure clearly shows difference and 
Fig. 12 Solid lines Asphaltene deposition profiles predicted by the four models along the axial length of Marrat oil wellbore. Black Solid Line Reported caliper measurement of the wellbore

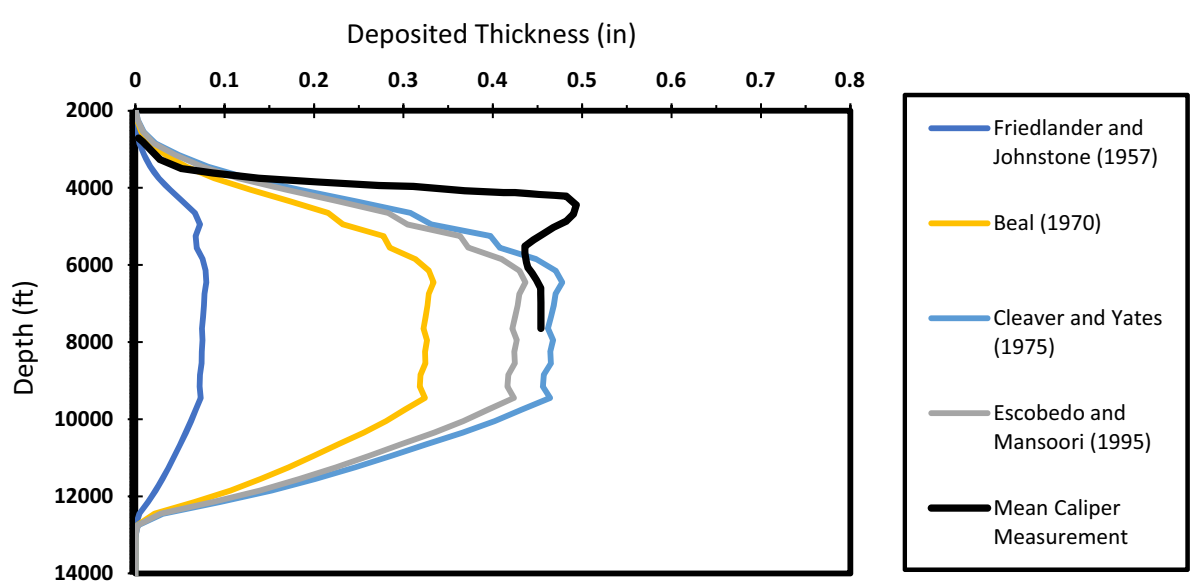

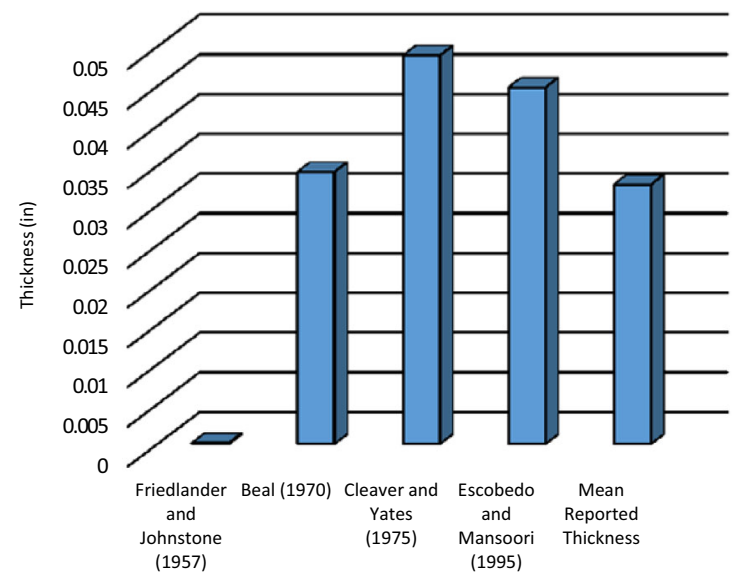

(a)

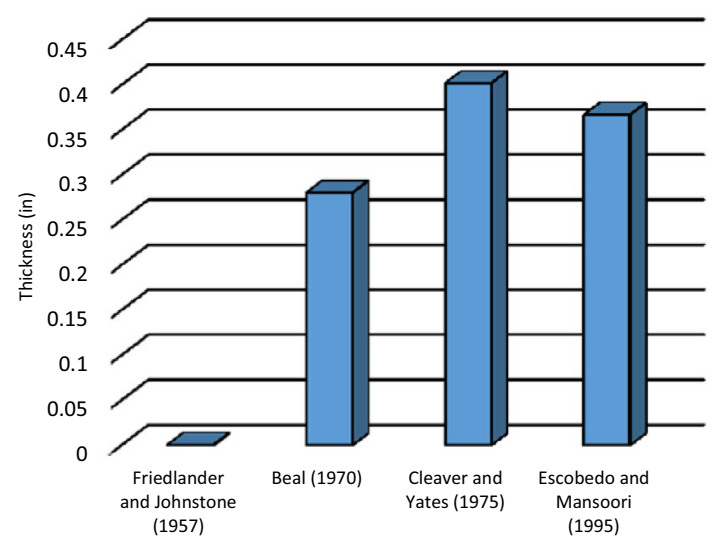

(c)

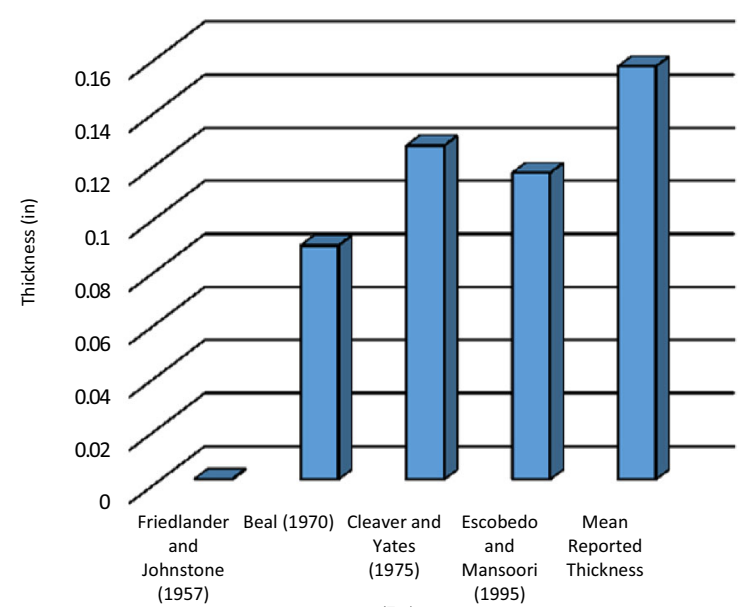

(b)

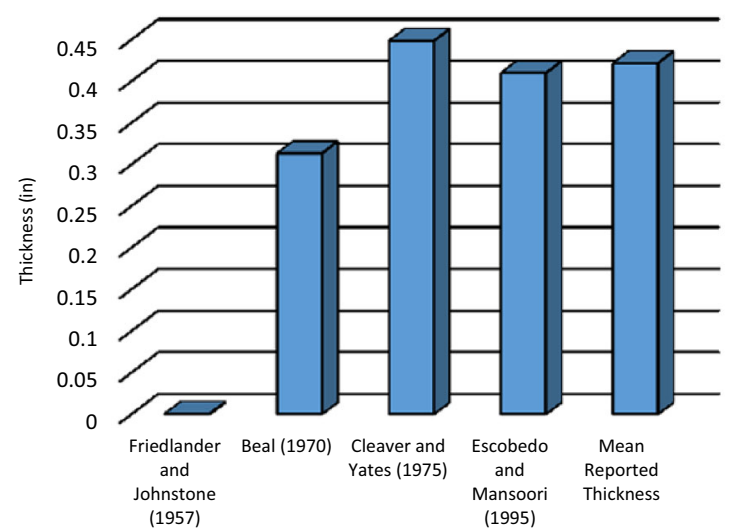

(d)

Fig. 13 Comparison of the model predictions with mean reported asphaltene thickness at four Reynolds numbers a 2500 (depth $\sim 3150 \mathrm{ft}$ ), b 2950 (depth $3750 \mathrm{ft}$ ), c 3500 (depth $\sim 10,000 \mathrm{ft}$ ), d 4000 (depth $\sim 5850 \mathrm{ft}$ )

similarity of model predictions with each other. Also, since in the last three Reynolds numbers, caliper measurements were available, we can notice that Friedlander and Johnstone (1957) model highly underestimate the thickness of deposited layer, while the Escobedo and Mansoori (1995) and Cleaver and Yates (1975) models predict the rate of asphaltene deposition higher than Beal (1970) model. 


\section{Conclusion}

In this work, five asphaltene particle deposition models were selected from the literature and were applied to the oil wellbore with measured deposition thickness. The deposition models were explained with particular attention to the assumptions and the way these models developed. To apply the models to the oil field wellbore, all available data about a Kuwait oil well were gathered for thermodynamic modeling of reservoir fluid and calculating the hydrodynamic conditions of the fluid along the wellbore. By employing the phase behavior of oil/asphaltene system, a graphical method was proposed for predicting the asphaltene precipitation zone along the wellbore. By applying the models to the studied oil well, we found that due to the small size of the asphaltene particles, the diffusion mechanism is dominant in the radial transport of the asphaltene particles toward the wall in Marrat oil well. After predicting the asphaltene transport coefficient, the concentration of precipitated asphaltene, and sticking probability along the oil well, comparison of the models with each other showed that Cleaver and Yates (1975) and Escobedo and Mansoori (1995) models approximately predict the asphaltene deposition in the same order. Comparison of the deposition models with measured caliper profile showed that Escobedo and Mansoori (1995) and Cleaver and Yates (1975) models perform well in predicting the deposition profile than other models, while Friedlander and Johnstone (1957) model had a very poor performance in this comparison. However, it should be noted that our conclusion on predictive capabilities of the models is valid just for studied oil well and generalization of findings to another well with different fluid characteristics and operation conditions must be avoided.

This paper contributed to a better understanding of asphaltene deposition process along production tubing during the reservoir natural depletion. However, there is still much to be investigated about this complex process. Systematic experimental work to understand the asphaltene adhesion/reentrainment (known as sticking probability) should be addressed in the future to make the selected models more complete and accurate to predict the asphaltene deposition profile.

Open Access This article is distributed under the terms of the Creative Commons Attribution 4.0 International License (http:// creativecommons.org/licenses/by/4.0/), which permits unrestricted use, distribution, and reproduction in any medium, provided you give appropriate credit to the original author(s) and the source, provide a link to the Creative Commons license, and indicate if changes were made.

\section{References}

Abouie A, Shirdel M, Darabi H, Sepehrnoori K (2015) Modeling asphaltene deposition in the wellbore during gas lift process. In: SPE Western Regional Meeting. Society of Petroleum Engineers
Abouie A, Darabi H, Sepehrnoori K (2016) Data-driven comparison between solid model and PC-SAFT for modeling asphaltene precipitation. In: Offshore technology conference

Adams JJ (2014) Asphaltene adsorption, a literature review. Energy Fuels 28:2831-2856

Akbarzadeh K, Eskin D, Ratulowski J, Taylor S (2011) Asphaltene deposition measurement and modeling for flow assurance of tubings and flow lines. Energy Fuels 26:495-510

Alboudwarej H, Svrcek WY, Kantzas A, Yarranton HW (2004) A pipe-loop apparatus to investigate asphaltene deposition. Pet Sci Technol 22:799-820

Arciniegas LM, Babadagli T (2014) Asphaltene precipitation, flocculation and deposition during solvent injection at elevated temperatures for heavy oil recovery. Fuel 124:202-211. doi:10. 1016/j.fuel.2014.02.003

Beal SK (1970) Deposition of particles in turbulent flow on channel or pipe walls. Nucl Sci Eng 40:1-11

Behbahani TJ, Ghotbi C, Taghikhani V, Shahrabadi A (2013) A modified scaling equation based on properties of bottom hole live oil for asphaltene precipitation estimation under pressure depletion and gas injection conditions. Fluid Phase Equilib 358:212-219

Cleaver J, Yates B (1975) A sub layer model for the deposition of particles from a turbulent flow. Chem Eng Sci 30:983-992

Epstein N (1997) Elements of particle deposition onto nonporous solid surfaces parallel to suspension flows. Exp Therm Fluid Sci 14:323-334

Escobedo J, Mansoori GA (1995) Asphaltene and other heavy-organic particle deposition during transfer and production operations. In: SPE annual technical conference and exhibition. Society of Petroleum Engineers

Fallahnejad G, Kharrat R (2015) Fully implicit compositional simulator for modeling of asphaltene deposition during natural depletion. Fluid Phase Equilib 398:15-25

Friedlander S, Johnstone H (1957) Deposition of suspended particles from turbulent gas streams. Ind Eng Chem 49:1151-1156

Gupta AK (1986) A model for asphaltene flocculation using an equation of state. Chemical and Petroleum Engineering, University of Calgary, Calgary

Hashmi S, Loewenberg M, Firoozabadi A (2015) Colloidal asphaltene deposition in laminar pipe flow: flow rate and parametric effects. Phys Fluids (1994-Present) 27:083302

Jafari Behbahani T, Ghotbi C, Taghikhani V, Shahrabadi A (2012) Investigation on asphaltene deposition mechanisms during $\mathrm{CO}_{2}$ flooding processes in porous media: a novel experimental study and a modified model based on multilayer theory for asphaltene adsorption. Energy Fuels 26:5080-5091

Jamaluddin A et al. (2002) Laboratory techniques to measure thermodynamic asphaltene instability. J Can Pet Technol 41(07):44-52

Jamialahmadi M, Soltani B, Müller-Steinhagen H, Rashtchian D (2009) Measurement and prediction of the rate of deposition of flocculated asphaltene particles from oil. Int J Heat Mass Transf 52:4624-4634

Juyal P et al (2013) Joint industrial case study for asphaltene deposition. Energy Fuels 27:1899-1908

Kabir C, Jamaluddin A (2002) Asphaltene characterization and mitigation in south Kuwait's Marrat reservoir. SPE Prod Facil 17:251-258

Kabir C, Hasan A, Lin D, Wang X (2001) An approach to mitigating wellbore solids deposition. In: SPE annual technical conference and exhibition. Society of Petroleum Engineers

Kurup AS, Vargas FM, Wang J, Buckley J, Creek JL, Subramani HJ, Chapman WG (2011) Development and application of an asphaltene deposition tool (ADEPT) for well bores. Energy Fuels 25:4506-4516

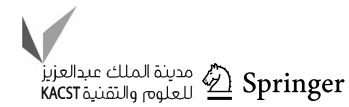


Lin C-S, Moulton R, Putnam G (1953) Mass transfer between solid wall and fluid streams. Mechanism and Eddy distribution relationships in turbulent flow. Ind Eng Chem 45:636-640

Mohebbinia S, Sepehrnoori K, Johns RT, Kazemi Nia Korrani A (2014) Simulation of asphaltene precipitation during gas injection using PC-SAFT EOS. In: SPE annual technical conference and exhibition. Society of Petroleum Engineers

Mullins OC, Sheu EY, Hammami A, Marshall AG (2007) Asphaltenes, heavy oils, and petroleomics. Springer, Berlin

Nasrabadi H, Moortgat J, Firoozabadi A (2016) New three-phase multicomponent compositional model for asphaltene precipitation during $\mathrm{CO} 2$ injection using CPA-EOS. Energy Fuels 30(4):3306-3319

Nghiem LX, Coombe DA (1997) Modeling asphaltene precipitation during primary depletion. SPE J 2:170-176

Nghiem L, Hassam M, Nutakki R, George A (1993) Efficient modelling of asphaltene precipitation. In: SPE annual technical conference and exhibition. Society of Petroleum Engineers

Paes D, Ribeiro P, Shirdel M, Sepehrnoori K (2015) Study of asphaltene deposition in wellbores during turbulent flow. J Pet Sci Eng 129:77-87

Peng D-Y, Robinson DB (1976) A new two-constant equation of state. Ind Eng Chem Fundam 15:59-64

Prakoso A, Punase A, Klock K, Rogel E, Ovalles C, Hascakir B (2016) Determination of the stability of asphaltenes through physicochemical characterization of asphaltenes. In SPE Western Regional Meeting, Society of Petroleum Engineers, Anchorage, Alaska, USA, 23-26 May 2016. doi: 10.2118/ 180422-MS

Prandtl L (1935) The mechanics of viscous fluids
Rassamdana H, Dabir B, Nematy M, Farhani M, Sahimi M (1996) Asphalt flocculation and deposition: I. The onset of precipitation. AIChE J 42:10-22

Sarma HK (2003) Can we ignore asphaltene in a gas injection project for light-oils? In: SPE international improved oil recovery conference in Asia Pacific. Society of Petroleum Engineers

Sedghi M, Goual L (2014) PC-SAFT modeling of asphaltene phase behavior in the presence of nonionic dispersants. Fluid Phase Equilib 369:86-94

Shirdel M, Paes D, Ribeiro P, Sepehrnoori K (2012) Evaluation and comparison of different models for asphaltene particle deposition in flow streams. J Pet Sci Eng 84:57-71

Tavakkoli M, Masihi M, Ghazanfari MH, Kharrat R (2011) An improvement of thermodynamic micellization model for prediction of asphaltene precipitation during gas injection in heavy crude. Fluid Phase Equilib 308:153-163

Tavakkoli M, Panuganti SR, Taghikhani V, Pishvaie MR, Chapman WG (2013) Precipitated asphaltene amount at high-pressure and high-temperature conditions. Energy Fuels 28:1596-1610

Vargas FM, Creek JL, Chapman WG (2010) On the development of an asphaltene deposition simulator $\dagger$. Energy Fuels 24:2294-2299

Watkinson AP (1968) Particulate fouling of sensible heat exchangers. University of British Columbia, Vancouver

Zeinali Hasanvand M, Mosayebi Behbahani R, Feyzi F, Ali Mousavi Dehghani S (2016) The effect of asphaltene particle size and distribution on the temporal advancement of the asphaltene deposition profile in the well column. Eur Phys J Plus 131:1-12. doi:10.1140/epjp/i2016-16150-3 